\title{
New WHO Violence Prevention Information System, an interactive knowledge platform of scientific findings on violence
}

\author{
Stephanie Burrows, ${ }^{1}$ Alexander Butchart, ${ }^{1}$ Nadia Butler, ${ }^{2}$ Zara Quigg, ${ }^{2}$ Mark A Bellis, ${ }^{3,4}$ \\ Christopher Mikton ${ }^{5}$
}

'Department for Management of Noncommunicable Diseases, Disability, Violence and Injury Prevention, World Health Organization, Geneva, Switzerland

${ }^{2}$ Faculty of Education, Health and Community, Public Health Institute, Liverpool John Moores University, Liverpool, UK

${ }^{3}$ College of Health and Behavioural Sciences, Normal Site, Bangor University, Bangor, UK

${ }^{4}$ Directorate of Policy, Research and International Development Public Health Wales, Wrexham, UK

${ }^{5}$ Independent researcher

\section{Correspondence to} Dr Stephanie Burrows, WHO Department for Management of Noncommunicable Diseases, Disability, Violence and Injury Prevention, Prevention of Violence Unit, 20 avenue Appia, 1211 Geneva 27, Switzerland; burrowss@who.int

Received 6 December 2017 Accepted 15 December 2017

Check for updates

To cite: Burrows $S$, Butchart $\mathrm{A}$, Butler $\mathrm{N}$, et al. Inj Prev 2018:24:155-156.

\section{ABSTRACT}

Scientific information on violence can be difficult to compile and understand. It is scattered across websites, databases, technical reports and academic journals, and rarely addresses all types of violence. In response, in October 2017 WHO released the Violence Prevention Information System or Violence Info, an online interactive collection of scientific information about the prevalence, consequences, risk factors and preventability of all forms of interpersonal violence. It covers homicide, child maltreatment, youth violence, intimate partner violence, elder abuse and sexual violence.

Violence Info (figure 1) has three primary sources of data:

1. Published scientific studies provide data on the prevalence, consequences, risk factors and effectiveness of prevention and response strategies. The data were extracted from systematic reviews and, in areas poorly covered by them, from single studies.

2. WHO Global Health Estimates provide global, regional and national homicide rates.

3. The WHO Global status report on violence prevention 2014 provides information on what countries reported about the existence of national action plans, social and educational policies, specific laws, prevention programmes and services for victims.

Violence Info is ambitious-a literature review and data synthesis on this scale is rare. The data repository currently contains almost 13000 individual data points, from over 3500 single studies. Data are presented on more than 120 different risk factors and for 45 different consequences across the different violence types. It includes study data on prevalence of the various types (eg, child maltreatment) and subtypes (eg, sexual abuse) of violence for 95 countries, including 59 low-income and middle-income countries. Summary estimates are provided for the effectiveness of more than 38 different intervention strategies for preventing and responding to violence.

Additionally, Violence Info presents homicide estimates for 183 countries/areas, by sex, age group and year (2000, 2005, 2010, 2015). Regional and global homicide estimates are also available. Information on national efforts to address interpersonal violence is presented for 133 countries.

Violence Info is structured as follows:
1. Dedicated pages for each violence type

These pages summarise data from published scientific studies on prevalence, consequences, risk factors, prevention and response strategies. A world map indicates which countries have studies on prevalence for a particular subtype of violence (eg, physical, sexual), the number of studies, the total sample size of those studies and the median prevalence value for those studies. Users can shift between the different subtypes of violence, and between country and WHO region.

Different visualisations show the relative importance of particular consequences of and risk factors for each violence type. Consequences are grouped as problems relating to health, social and behavioural issues, cognitive and academic performance, and economic issues. Risk factors are organised according to the social ecological model of violence with its four levels: individual, relationship, community and societal. ${ }^{1}$ Within each type of violence and for both prevention and response strategies, Violence Info provides the number of studies, sample size and the range of effectiveness across different interventions. A section also summarises key elements of those interventions with evidence of effectiveness. Details of the survey instruments most widely used to measure the prevalence of each violence type are also summarised.

2. Study pages

Data from published scientific studies can be explored in more depth in the Studies section through a series of interactive visualisations. The studies are organised first by violence type and then by prevalence, consequences, risk factors, prevention and response strategies. The data can be filtered by several variables such as author, sex, age or country income group.

3. Country pages

The Countries section includes data for WHO Member States and areas. Each country page displays the types of violence for which study data are available; national homicide rates (from WHO Global Health Estimates); and national efforts to address interpersonal violence (from WHO Global status report on violence prevention 2014).

Violence Info has several interactive features. By hovering and/or clicking on the world maps and visualisations, users are provided with more 


\section{VIOLENCE INFO}

(4) Word heath

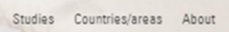

\section{INTERPERSONAL VIOLENCE AFFECTS HUNDREDS OF MILLIONS OF PEOPLE. BUT IT CAN BE PREVENTED.}
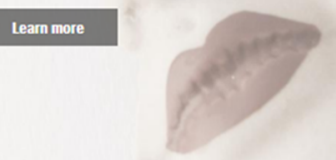

Figure 1 WHO Violence Prevention Information System, an interactive knowledge platform of scientific findings on violence.

fine-grained information for the particular violence type being examined. Help tools are provided throughout the web site and a methodology document is available for download. Images from the site can be downloaded, shared and embedded in other documents and web sites. The study data and homicide estimates can also be downloaded as Excel files.

The development of Violence Info is a collaborative undertaking between WHO, Liverpool John Moores University and Public Health Wales. Violence Info is designed to support local, national and international violence prevention policy developments, interventions or other activities. We would welcome the views of those who might contribute to or use such a tool both on its current utility and on how this might be enhanced. The web site will be periodically updated as new scientific studies become available. Access Violence Info at http://apps.who.int/ violence-info/

\section{RELATED LINKS}

Violence Info

http://apps.who.int/violence-info/

WHO Prevention of Violence Unit

http://www.who.int/violence_injury_prevention/violence/en/

\section{WHO Global Health Estimates}

http://www.who.int/healthinfo/global burden disease/en/ Global status report on violence prevention 2014

http://www.who.int/violence_injury_prevention/violence/ status_report/2014/en/

Contributors $S B$ and $A B$ coordinate and manage Violence Info. CM initiated the project, and together with $M A B$ conceptualised it. NB and $Z Q$ were responsible for developing the methodology, and manage ongoing extraction and preparation of data. All authors contributed to the writing and approved the final manuscript. SB is responsible for the overall content as guarantor.

Disclaimer SB and AB are staff members of the World Health Organization. They alone are responsible for the views expressed in this update and they do not necessarily represent the decisions or policies of the World Health Organization.

Competing interests None declared.

Provenance and peer review Not commissioned; internally peer reviewed.

(c) Article author(s) (or their employer(s) unless otherwise stated in the text of the article) 2018. All rights reserved. No commercial use is permitted unless otherwise expressly granted.

\section{REFERENCE}

1 Krug E, Dahlberg L, Mercy J, et al. World report on violence and health. Geneva: World Health Organization, 2002. 